
mogango. Horticultura Brasileira 32: 80-85.

\title{
Salinidade e desempenho fisiológico de sementes e plântulas de mogango
}

\author{
Letícia SH Harter; Fábio S Harter; Cristiane Deuner; Géri E Meneghello; Francisco A Villela
}

FAEM-UFPel, C. Postal 354, 96010-900 Pelotas-RS; 1sholbig@yahoo.com.br; fabiosharter@yahoo.com.br; cdeuner@yahoo.com.br; geriem@ufpel.edu.br; francisco.villela@ufpel.edu.br

\section{RESUMO}

O mogango (Cucurbita pepo) apresenta multiplicação por sementes, via semeadura direta ou em bandejas para posterior transplante, sendo indispensável a utilização de sementes com elevado vigor. Para que as sementes germinem é necessário que existam condições favoráveis de oxigênio, temperatura e disponibilidade de água, mas nem sempre essas condições são adequadas, especialmente em solos salinos. O objetivo desta pesquisa foi avaliar a influência de diferentes concentrações salinas na manifestação da qualidade fisiológica de sementes e na expressão dos sistemas isoenzimáticos em plântulas de mogango. Foram utilizadas sementes de mogango, cv. Sul Mineiro, submetidas às concentrações salinas de $0,25,50,75$ e $100 \mathrm{mM}$ no substrato. A resposta das sementes a essas variações foi avaliada pelos testes de germinação (computando-se a primeira contagem de germinação e porcentagem de plântulas normais e anormais), comprimento de parte aérea e sistema radicular, índice de área foliar, fitomassa seca (parte aérea e raiz) e isoenzimas (superóxido dismutase, peroxidase e esterase). Sob condições de estresse salino, sementes de mogango, cultivar Sul Mineiro, apresentam dificuldades para a germinação e desenvolvimento de plântulas; estas ativam mecanismo de defesa com maior expressão no sistema radicular.

Palavras-chave: Cucurbita pepo, estresse salino, vigor, expressão enzimática.

\begin{abstract}
Effect of salinity on physiological performance of mogango seeds and seedlings

The mogango (Cucurbita pepo) is multiplied directly by seeds or indirectly by sowing in trays for subsequent transplanting and the use of highly vigorous seeds is important. Seed germination requires favorable conditions of oxygen, temperature and water availability, but these conditions are not always appropriate, especially in saline soils. The objective of this research was to evaluate the influence of different salt concentrations in the manifestation of physiological seed quality and expression of isoenzyme systems in mogango seedlings. We evaluated seeds of mogango, cv. Sul Mineiro, subjected to salt concentrations of $0,25,50,75$ and $100 \mathrm{mM}$ in the substrate. The response of seeds to these variations was evaluated by germination (first count and percentage of normal and abnormal seedlings), length of shoot and root system, leaf area index, shoot and root dry matter and isoenzymes (superoxide dismutase, peroxidase and esterase) activity. Squash seed performance, cv. Sul Mineiro, was affected under salt stress. In this situation, seedlings activate a defense mechanism with higher expression in the root system.
\end{abstract}

Keywords: Cucurbita pepo, salt stress, vigor, enzyme expression.

(Recebido para publicação em 22 de janeiro de 2013; aceito em 12 de fevereiro de 2014) (Received on January 22, 2013; accepted on February 12, 2014)

$\mathrm{O}$ mogango (Cucurbita pepo) pertence à família das cucurbitáceas. No Brasil, é muito cultivado no estado do Rio Grande do Sul, sendo muito apreciado na culinária. $\mathrm{O}$ mogango é multiplicado por semeadura direta ou, indiretamente em bandejas com células individuais para posterior transplantio, sendo indispensável a utilização de sementes com elevado vigor (Malone et al., 2008).

No Brasil, a área afetada pelo estresse salino corresponde a $2 \%$ da área total (Menezes-Benavente et al., 2004), sendo grande obstáculo à produtividade das lavouras, especialmente no Rio Grande do Sul, onde o sistema de irrigação ocorre principalmente por inundação e a água usada para irrigação provém de rios abastecidos por lagoas costeiras, podendo conduzir à salinização dos solos que possuem drenagem inadequada, impedindo a remoção do sal por lixiviação.

Para que as sementes germinem é necessário que existam condições favoráveis de oxigênio, temperatura e disponibilidade de água (Carvalho \& Nakagawa, 2000). Entretanto, nem sempre essas condições são adequadas, especialmente em solos salinos.

A alta concentração de sais é um fator de estresse para as plantas, pois reduz o potencial osmótico e proporciona a ação dos íons sobre o protoplasma. A água é osmoticamente retida na solução salina, de forma que o aumento da concentração de sais a torna cada vez menos disponível para as plantas (Ribeiro et al., 2001). Assim, com o aumento da salinidade ocorre diminuição do potencial osmótico do solo, dificultando a absorção de água pelas raízes (Amorim et al., 2002; Lopes \& Macedo, 2008).

As sementes também sofrem influência significativa da condição de salinidade dos solos. O alto teor de sais, especialmente de cloreto de sódio $(\mathrm{NaCl})$, pode inibir a germinação devido à diminuição do potencial osmótico, ocasionando prejuízos às demais fases do processo (Lima et al., 2005).

Um dos métodos mais difundidos para determinação da tolerância das plantas ao excesso de sais é a observação da porcentagem de germinação em substratos salinos (Lima \& Torres, 
2009). A redução do poder germinativo, em comparação com o controle, serve como um indicador do índice de tolerância da espécie à salinidade (Góis et al., 2008). Nesse método, a habilidade para germinar indica, também, a tolerância das plantas aos sais em estádios subsequentes do desenvolvimento (Taiz \& Zeiger, 2006).

O estudo da tolerância à salinidade em plantas é de especial importância, pois o sal se constitui em fator limitante para a produção agrícola, causando dois tipos distintos de estresse: estresse osmótico e estresse por fitotoxicidade iônica específica, o que consequentemente diminui a absorção de nutrientes e o crescimento, provocando distúrbios nas atividades metabólicas em geral.

$\mathrm{Na}$ tecnologia de sementes, uma das maiores dificuldades para avaliar a qualidade de sementes refere-se à metodologia para execução dos testes. Dessa forma, novos testes devem ser desenvolvidos para obter resultados efetivos e mais rápidos, na tentativa de estimar o desempenho dos lotes que chegam ao laboratório (Tunes et al., 2010). A eletroforese vem sendo utilizada no estudo de isoenzimas com relação, não apenas em mudanças da qualidade fisiológica de sementes, mas também nas regulações gênica e bioquímica, entre outros.

Desta forma, o objetivo desta pesquisa foi avaliar a influência de diferentes concentrações salinas na qualidade fisiológica de sementes, e os sistemas enzimáticos em plântulas de mogango.

\section{MATERIAL E MÉTODOS}

A pesquisa foi conduzida no Laboratório Didático de Análise de Sementes (LDAS), da Faculdade de Agronomia Eliseu Maciel, da Universidade Federal de Pelotas.

Foram utilizadas sementes de mogango, cv. Sul Mineiro, submetidas a diferentes concentrações salinas 0 (controle), $25 \mathrm{mM}\left(1,462 \mathrm{~g} \mathrm{~L}^{-1} \mathrm{de} \mathrm{NaCl}\right)$, $50 \mathrm{mM}\left(2,925 \mathrm{~g} \mathrm{~L}^{-1} \mathrm{de} \mathrm{NaCl}\right), 75 \mathrm{mM}$ $\left(4,387 \mathrm{~g} \mathrm{~L}^{-1} \mathrm{de} \mathrm{NaCl}\right)$ e $100 \mathrm{mM}(5,850$ $\mathrm{g} \mathrm{L}^{-1}$ de $\mathrm{NaCl}$ ). O substrato utilizado na condução dos testes de avaliação da qualidade das sementes foi embebido com soluções salinas com os diferentes potenciais osmóticos.

A qualidade fisiológica foi avaliada pelos testes: Germinação - conduzido com quatro subamostras de 50 sementes em rolos de papel germitest, por unidade experimental, umedecido com soluções na proporção 2,5 vezes o seu peso seco, transferidas para germinador a $25^{\circ} \mathrm{C}$. As avaliações foram realizadas no quarto e oitavo dia após a semeadura, computando-se as porcentagens de plântulas normais e anormais (Brasil, 2009); Primeira contagem do teste de germinação - representada pelo registro realizado juntamente ao teste de germinação avaliando-se as plântulas normais, no quarto dia após a semeadura do teste de germinação (Nakagawa, 1999); Comprimento de plântulas - quinze plântulas normais, de cada repetição, obtidas de maneira aleatória da contagem final do teste de germinação, foram medidas com o auxílio de régua graduada, obtendo-se os comprimentos de parte aérea e do sistema radicular. Os resultados foram expressos pelo valor médio por plântula, em cm, em cada unidade experimental (Nakagawa, 1999); Índice de área foliar - utilizaram-se as mesmas plântulas usadas para avaliação do comprimento de plântulas. Cada parte aérea foi avaliada individualmente em um medidor de área foliar modelo LI3100/Área Meter, sendo obtidos valores médios por repetição; Fitomassa seca (plântula) - após a avaliação da área foliar e do comprimento de parte aérea e do sistema radicular, o material foi acondicionado em cápsulas de alumínio e seco em estufa com circulação de ar forçado na temperatura de $60 \pm 2^{\circ} \mathrm{C}$, por 72 horas. As amostras foram então colocadas em dessecador contendo sílica para resfriamento e posterior pesagem em balança analítica com precisão de 0,0001 g (Nakagawa, 1999); Isoenzimas - As avaliações da atividade das enzimas superóxido dismutase (SOD), peroxidase (PO) e esterase (EST) foram realizadas utilizando-se o sistema de eletroforese vertical em gel de poliacrilamida. O material vegetal composto de 10 plântulas com oito dias, de cada tratamento, foi macerado em mortar de porcelana sobre cubos de gelo. Aproximadamente $200 \mathrm{mg}$ de cada extrato vegetal foram colocados em tubo de microcentrífuga acrescidos de solução extratora composta pelo tampão do gel (borato de lítio 0,2 $\mathrm{M}$ a pH 8,3 + Tris Citrato $+0,2 \mathrm{M}$ a pH 8,3) $+0,15 \%$ de 2-mercaptoetanol) na proporção 1:2 $(\mathrm{p} / \mathrm{v})$. Realizou-se a eletroforese em géis de poliacrilamida $7 \%$, aplicando-se 20 $\mu \mathrm{L}$ de cada amostra. Foram utilizados os sistemas de coloração descritos por Alfenas (1998). A interpretação dos resultados foi baseada na análise visual dos géis de eletroforese, levando-se em consideração a presença e a ausência e a intensidade de expressão de cada uma das bandas.

O experimento foi conduzido com delineamento inteiramente casualizado com quatro repetições. Para análise estatística utilizou-se o programa estatístico Winstat (Machado, 2002), sendo as médias submetidas à análise de variância e análise de regressão polinomial.

\section{RESULTADOS E DISCUSSÃO}

Analisando os dados obtidos e interpretando a análise de regressão, foi observado efeito significativo das concentrações salinas sobre a germinação de sementes de mogango, (Figura 1A), onde na ausência do $\mathrm{NaCl}$ as sementes apresentaram em média germinação de $85 \%$, obtendo uma redução discreta nas concentrações de 25 e $50 \mathrm{mM}$ e mais acentuada a partir da concentração de $75 \mathrm{mM}$, chegando a valores inferiores a $30 \%$ na maior concentração avaliada. De maneira geral, a salinidade provoca efeito negativo sobre a germinação de sementes; entretanto, este comportamento varia com a espécie e as concentrações testadas. Até a concentração de 100 mM, Deuner et al. (2011) observaram que sementes de feijão-miúdo (Vigna unguiculata) não apresentaram redução na germinação.

Trabalhando com sementes de cevada, Silva et al. (2007) observaram redução na porcentagem de germinação com o aumento da concentração de sal, indicando que o $\mathrm{NaCl}$ reduziu a viabilidade das sementes.

A primeira contagem do teste de germinação (Figura 1B) caracterizou o efeito do estresse salino na velocidade de germinação, sendo observada ten- 


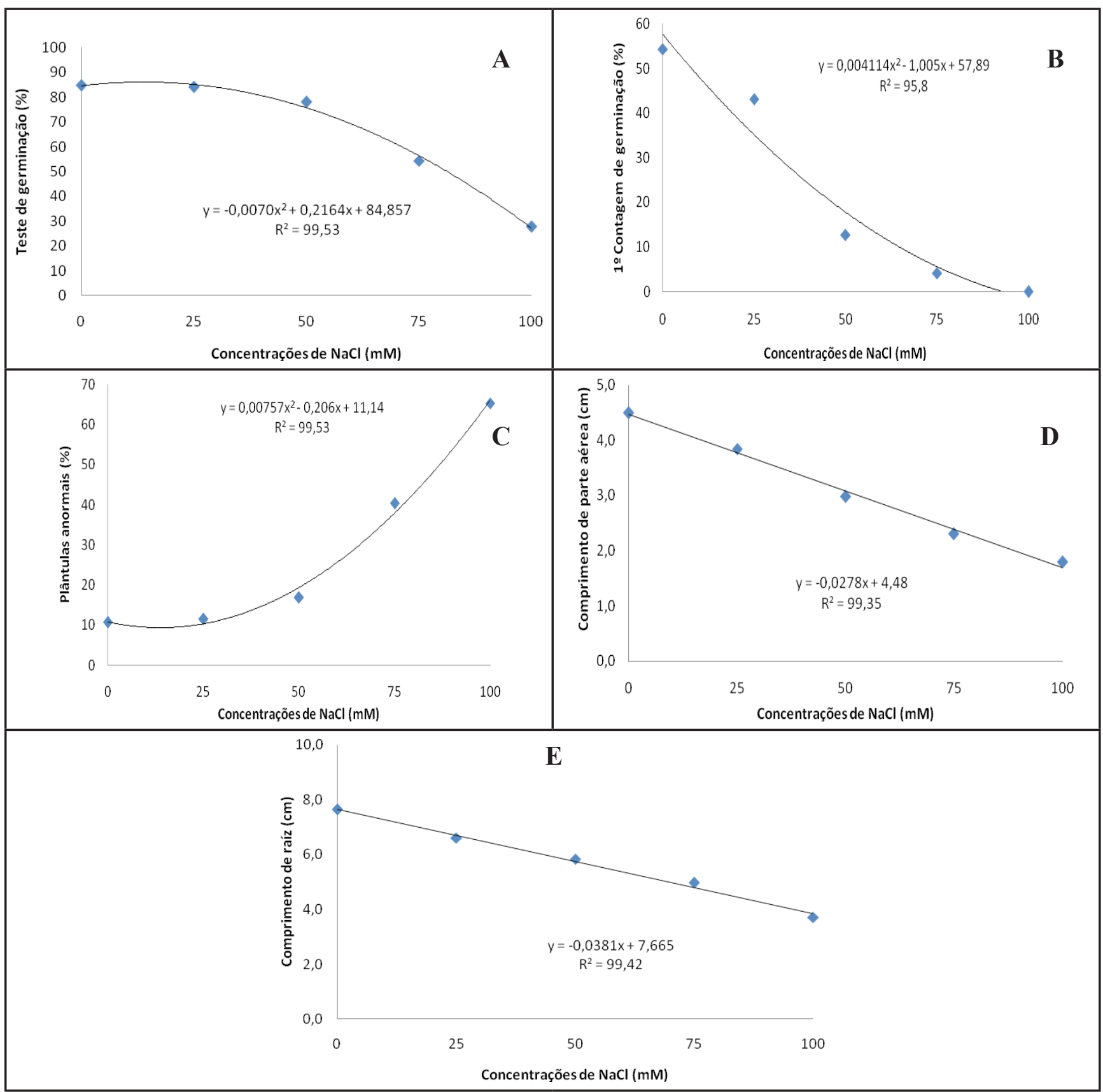

Figura 1. Teste de germinação (A), primeira contagem do teste de germinação (B), plântulas anormais (C), comprimento da parte aérea (D) e comprimento da raiz primária(E) de plântulas oriundas de sementes de mogango (Curcubita pepo) expostas a diferentes concentrações de cloreto de sódio [germination test (A), first count of germination (B), abnormal seedlings (C), shoot length (D) and root length (E) of mogango seedlings (Curcubita pepo) from seeds exposed to different concentrations of sodium chloride]. Pelotas, UFPel, 2011.

dência de redução para esta variável, de modo que na concentração de 100 $\mathrm{mM}$ ainda não houve germinação. Em sementes de feijão-miúdo, Deuner et al. (2011) observaram o mesmo comportamento, ressaltando que na concentração de $50 \mathrm{mM}$ houve redução da germinação na primeira contagem.

A porcentagem de plântulas anormais (Figura 1C) foi altamente influenciado pelo aumento nas concentrações de $\mathrm{NaCl}$, apresentando em média $11 \%$ de plântulas anormais na concentração zero e atingindo $65 \%$ na concentração de $100 \mathrm{mM}$ de $\mathrm{NaCl}$. A germinação diminuiu de forma mais acentuada a partir da concentração $50 \mathrm{mM}$. Trabalhando com sementes de pepino, Torres et al. (2000) constataram também o crescente aumento na ocorrência de plântulas anormais à medida que o potencial osmótico da solução era reduzido.
Para Van Der Moezel \& Bell (1987), o cloreto de sódio, afeta negativamente a germinação pelo efeito osmótico e/ou iônico, dificultando a absorção de água ou facilitando a penetração de íons nas células. Porém, o comportamento das plantas em relação à salinidade pode variar de acordo com o seu estádio de desenvolvimento, embora não tenha sido comparado se isto é devido à suscetibilidade a salinidade em determinado 


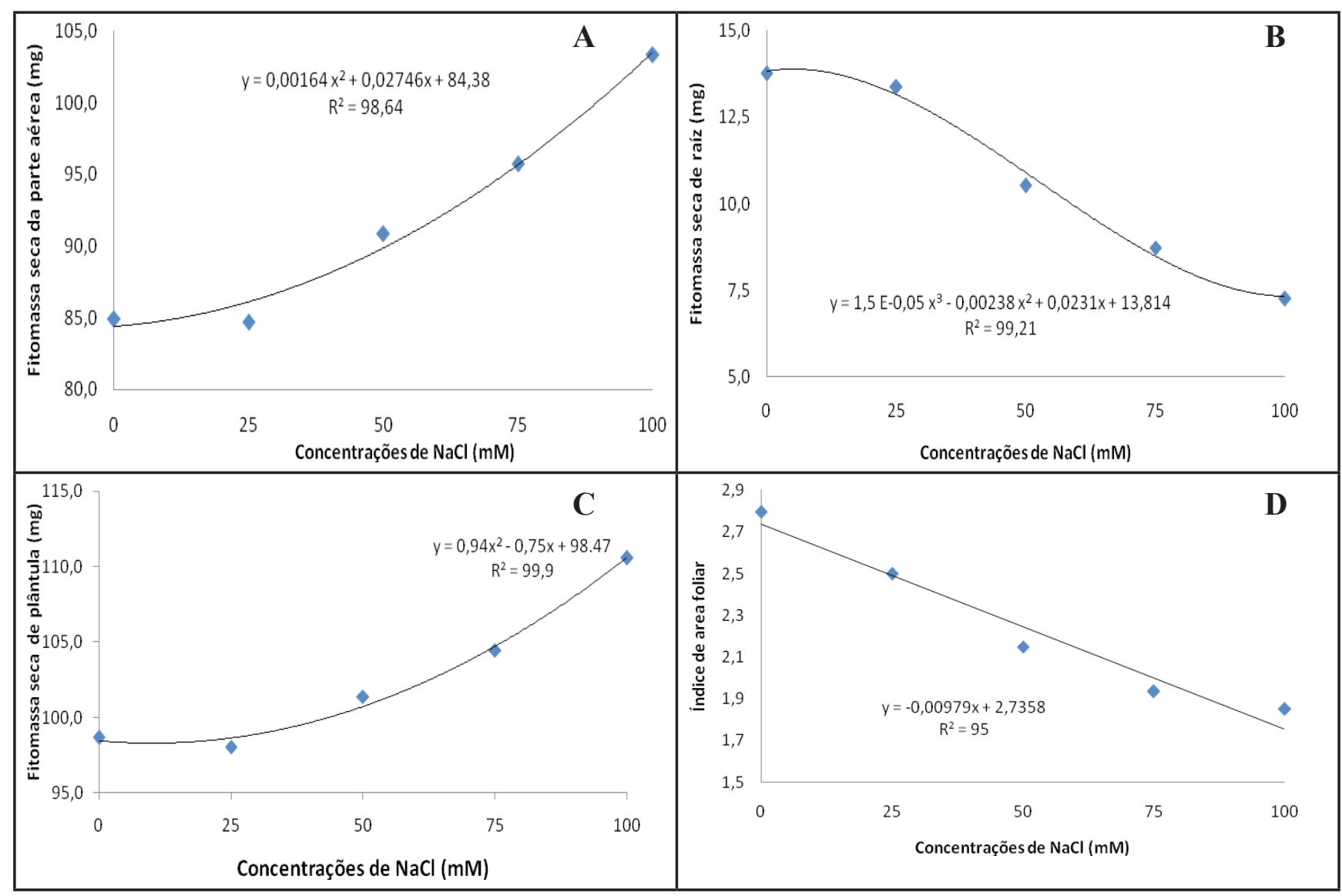

Figura 2. Fitomassa seca de parte aérea (A), fitomassa seca de raiz (B), fitomassa seca de plântulas (C) e índice de área foliar de plântulas (D) oriundas de sementes de mogango (Curcubita pepo) submetidas a diferentes concentrações de cloreto de sódio [dry mass of shoots (A), root dry weigth (B), seedling dry weight (C) and leaf area index of mogango seedlings (Curcubita pepo) (D) from seeds exposed to different concentrations of sodium chloride]. Pelotas, UFPel, 2011.

estádio de crescimento ou ao longo do período em que a planta ficou exposta ao substrato salino, ou a interação entre esses fatores.

Analisando as variáveis comprimento de parte aérea e de raiz (Figura 1D e 1E), foi observado que ambas apresentaram comportamento semelhante, havendo efeito linear decrescente com o aumento das concentrações de $\mathrm{NaCl}$, com decréscimo mais acentuado no comprimento de raiz. Resultados semelhantes foram observados em sementes de Chorisia glaziovi por Guedes et al. (2011); esses autores verificaram que o comprimento de raiz e de parte aérea foram afetados a medida em que houve aumento nos níveis de salinidade. Estes resultados estão de acordo com Dickmann et al. (2005), os quais trabalhando com sementes de girassol, concluíram que soluções salinas com potenciais osmóticos mais negativos produzem decréscimo no vigor de sementes, que pode ser avaliado pelo comprimento de plântula.

A fitomassa seca da parte aérea (Figura 2A) apresentou comportamento diferenciado das demais variáveis, pois com o aumento das concentrações de cloreto de sódio houve incremento na fitomassa seca, a partir da concentração de $25 \mathrm{mM}$ atingindo uma diferença de aproximadamente $24 \%$ entre o tratamento zero e a maior concentração testada. No entanto, na variável fitomassa seca de raiz houve redução na massa das raízes com o aumento das concentrações a partir da concentração $25 \mathrm{mM}$ (Figura 2B); discordando dos resultados obtidos por Secco et al . (2010) que, trabalhando com sementes de melão, observaram aumento no peso de matéria seca, nas sementes submetidas a estresse por salinidade; esses mesmos autores afirmam que tal fato deve-se ao acumulo de nutrientes na raiz.

Em arroz a presença de cloreto de sódio não interferiu na fitomassa das plântulas nos estágios iniciais de crescimento, sendo que normalmente, em plantas sensíveis à salinidade, ocorre diminuição da taxa de emergência e redução nas fitomassas seca e fresca da parte aérea e do sistema radicular (Lima et al., 2005).

A fitomassa seca da plântula (Figura 2C), que corresponde ao somatório da fitomassa da parte aérea e das raízes, apresentou comportamento similar ao da fitomassa da parte aérea, havendo aumento na massa com a elevação da concentração de sal, a partir da concentração de $25 \mathrm{mM}$.

O índice de área foliar apresentou comportamento semelhante à maioria das variáveis, pois o aumento do estresse salino ocasionou redução no índice de área foliar de maneira linear (Figura 2D). Estes resultados corroboram com os observados por Melo et al. (2006) que constataram a ocorrência de resposta 


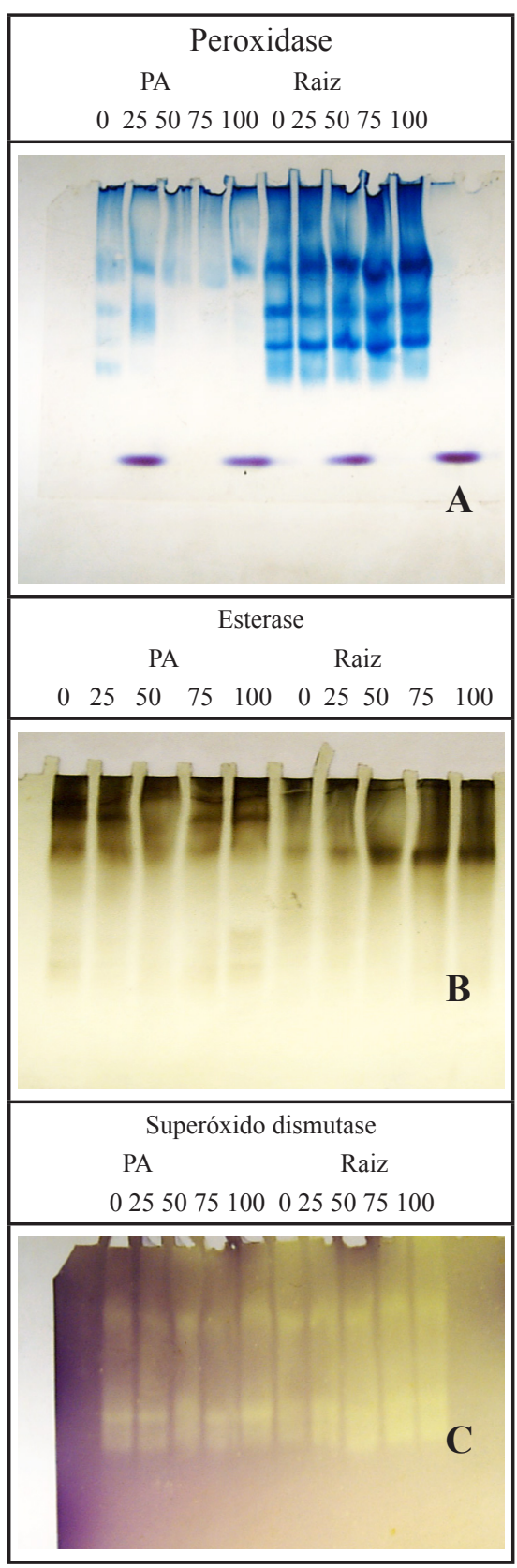

Figura 3. Padrão eletroforético obtido com o sistema isoenzimático peroxidase (A), esterase (B) e superóxido dismutase (C) em tecido da parte aérea e raiz de plântulas de mogango, a partir de sementes expostas a diferentes concentrações de cloreto de sódio [electrophoretic pattern obtained with the isoenzimatic peroxidase system (A), esterase (B) and superoxide dismutase (C) tissue in the shoot and root of mogango seedlings obtained from seeds exposed to different concentrations of sodium chloride]. Pelotas, UFPel, 2011.

linear ao aumento da condutividade elétrica do solo, pela maior concentração salina, de forma que com o aumento da concentração salina há redução na área foliar.

Diferentemente, em sementes de pinhão-manso, Andréo-Souza et al. (2010) observaram que os tratamentos com solução de salina de $4 \mathrm{dS} \mathrm{m}^{-1}$, foi benéficos na expansão foliar, e consequentemente aumentou a área foliar. Para esses autores, essa ocorrência indica tolerância das plântulas ao estresse salino.

A enzima peroxidase está envolvida em diversas funções nas plantas, formando ligações com polissacarídeos, participando na cicatrização de ferimentos, na defesa contra patógenos e regulação e elongação de células. No presente trabalho, a atividade de enzima (Figura 3A), não foi expressiva na avaliação através da eletroforese em gel de poliacrilamida em tecido da parte aérea de plântulas de mogango submetidas ao estresse salino. Porém, nas raízes houve formação de três bandas, sendo mais intensas na maior concentração salina (100 mM de $\mathrm{NaCl})$.

Estes resultados são concordantes com Mittal \& Dubey (1991), ao constatarem também aumento na atividade da peroxidase em plantas cultivadas em meio salino.

A variação observada na atividade da peroxidase pode ser uma adaptação do tecido vegetal à condição imposta (Gaspar et al., 1985), pois pode ocorrer incremento da oxidação dos lipídeos da membrana sob condições de estresse; o aumento da atividade da peroxidase devido à salinidade poderia indicar papel protetor da enzima contra o estresse. A peroxidase agiria como barreira contra o efeito danoso do estresse pelo desdobramento de substâncias tóxicas geradas como peróxidos e compostos fenólicos (Gangopadhyay et al., 1996). A alta atividade da peroxidase em plantas mantidas em estresse salino, poderia indicar um grau mais elevado do metabolismo oxidativo nestas células, principalmente em raízes, que são estruturas que ficam em contato direto com a solução (Srivastava et al., 1995).

A enzima esterase, constituída por um complexo e heterogêneo grupo de enzimas reativas com ampla gama de substratos específicos, expressou atividade em ambos os tecidos para todos os tratamentos. No entanto, nas raízes, para os tratamentos com 50, 75 e 100
mM de cloreto de sódio houve formação de bandas mais intensas, caracterizando maior atividade da referida enzima (Figura 3B).

Resultados semelhantes foram obtidos por Padilha et al. (2001) que verificaram aumento da intensidade das bandas para os estresses mais drásticos em sementes de milho e por Bock (1999), que analisaram avanço no número de bandas desta enzima, em sementes de cevada e soja, respectivamente. Analisando a atividade da esterase em cultivares de cevada submetidas a diferentes concentrações salinas, Tunes et al. (2010) verificaram que, conforme aumenta a concentração de cloreto de sódio, incrementa a intensidade das bandas em todas as épocas de colheita. Segundo Silva et al. (2000), essa indução pelo cloreto de sódio pode ser decorrente da sensibilidade dessa enzima à interferência de fatores abióticos.

A enzima superóxido dismutase, que atua na primeira linha de defesa contra as EROs (espécies reativas de oxigênio), dismutando o superóxido (O2-) a peróxido de hidrogênio $\left(\mathrm{H}_{2} \mathrm{O}_{2}\right)$, não apresentou diferença expressiva de intensidade de bandas, tanto na parte aérea quanto na raiz, nas diferentes concentrações de sal (Figura 3C). Este comportamento sugere que as diferentes concentrações de cloreto de sódio testadas não intensificaram maior atividade da enzima superóxido dismutase, fator que pode estar relacionado à maior atividade da peroxidase e esterase observada nas raízes nas maiores concentrações de sal, atuando em defesa ao estresse.

Desta forma, é possível observar que as plântulas de mogango submetidas ao estresse salino ativam seu mecanismo de defesa contra o estresse, sendo mais expressivo nas raízes do que na parte aérea, o que pode ser atribuído à maior sensibilidade do sistema radicular.

Com base nos resultados obtidos, pode-se concluir que, quando expostas a estresse salino, sementes de mogango, cultivar Sul Mineiro, apresentam dificuldades para a germinação e desenvolvimento de plântulas; estas ativam mecanismo de defesa com maior expressão no sistema radicular. 


\section{REFERÊNCIAS}

ALFENAS AC. 1998. Eletroforeses de isoenzimas e proteinas afins: fundamentos e aplicações em plantas e microorganismos. Viçosa: UFV. $574 \mathrm{p}$.

AMORIM JRA; FERNANDES PD; GHEYI HR; AZEVEDO NC. 2002. Efeito da salinidade e modo de aplicação à água de irrigação no crescimento e produção de alho. Pesquisa Agropecuária Brasileira 37: 167-176.

ANDRÉO-SOUZA Y; PEREIRAAL; SILVA FFS; RIEBEIRO-REIS RC; EVANGELISTA MRV; CASTRO RD; DANTAS BF. 2010. Efeito da salinidade na germinação de sementes e no crescimento inicial de mudas de pinhãomanso. Revista Brasileira de Sementes 32: 083-092.

BOCK FL. 1999. Resposta a nivel molecular do envelhecimento artificial, natural e précondicionamento de sementes de soja. Pelotas: UFPel. 27p (Tese mestrado).

BRASIL. MAPA. 2009. Regras para análise de sementes. Ministério da Agricultura, Pecuária e Abastecimento. Secretaria de Defesa Agropecuária. Brasília, DF: Mapa/ACS. 395p.

CARVALHO NM; NAKAGAWA J. 2000. Sementes: ciência, tecnologia e produção. Jaboticabal: FUNEP. 588p.

DEUNER C; MAIA MS; DEUNER S; ALMEIDA AS; MENEGHELLO GE. 2011. Viabilidade e atividade antioxidante de sementes de genótipos de feijão-miúdo submetidos ao estresse salino. Revista Brasileira de Sementes 33: 711-720.

DICKMANN L; CARVALHO MAC; BRAGA LF; SOUSA MP. 2005. Comportamento de sementes de girassol (Heliantus annuus L.) submetidas a estresse salino. Revista de Ciências Agro-Ambientais 3: 64-75.

GANGOPADHYAY G; SANGITA B; MUKHERJEE BB; GUPTA S. 1996. Salinityinduced changes on peroxidases in Nicotiana tabacum (var. Jayasri) callus cultures. Indian Journal of Plant Physiology 1: 247-250.

GASPAR T; PENEL C; CASTILLO FJ; GREPPIN HA. 1985. A two step control of basic and acid peroxidase and its significance for growth and development. Physiologia Plantarum
64: 418-423.

GÓIS VA; TORRES SB; PEREIRA RA. 2008. Germinação de sementes de maxixe submetidas a estresse salino. Revista Caatinga 21: 64-67.

GUEDES RS; ALVES EU; GALINDO EA; BARROZO LM. 2011. Estresse salino e temperaturas na germinação e vigor de sementes de Chorisia glaziovii O.Kuntze. Revista Brasileira de Sementes 33: 279-288.

LIMA BG; TORRES SB. 2009. Estresse hídrico e salino na germinação de sementes de Zizphus joazeiro Mart (Rhammaceae). Revista Caatinga 22: 93-99.

LIMA MGS; LOPES NF; MORAES DM; ABREU CM. 2005. Qualidade fisiológica de sementes de arroz submetidas a estresse salino. Revista Brasileira de Sementes 27: 54-61.

LOPES JC; MACEDO CMP. 2008. Germinação de sementes de sob influência do teor de substrato e estresse salino. Revista Brasileira de Sementes 30: 79-85.

MACHADO A. 2002. Programa de Análise Estatística - winstat 2. Disponível em: http:/www.ufpel.tche.br/ amachado/winstat/ software. Acessado em 15 de outubro de 2010.

MALONE PFVA; VILLELA FA; MAUCH CR. 2008. Potencial fisiológico de sementes de mogango e desempenho das plantas no campo. Revista Brasileira de Sementes 30: 123-129.

MELO PCS; ANUNCIAÇÃO FILHO CJ; OLIVEIRA J; BASTOS GQ; TABOSA JN; SANTOS VF. 2006. Seleção de genótipos de arroz tolerantes à salinidade durante a fase vegetativa. Ciência Rural 36: 58-64.

MENEZES-BENAVENTE L; TEIXEIRA FK; KAMEI CLA; MARGISPINHEIRO M. 2004. Salt stress induces altered expression of genes encoding antioxidant enzymes in seedlings of a Brazilian Indica rice (Oryza sativa L.). Plant Science 166: 323-331.

MITTAL R; DUBEY RS. 1991. Behaviour of peroxidases in rice: changes in enzyme activity and isoforms in relation to salt tolerance. Plant Physiology Biochemistry 29: 31-40.

NAKAGAWA J. 1999. Testes de vigor baseados no desempenho das plântulas. In.: KRZYZANOWSKI FC; VIEIRA RD; FRANÇA NETO JB (eds). Vigor de sementes: conceitos e testes. Londrina: ABRATES. p. 2.1-2.24.

PADILHA L; VIEIRA MGGC; VON PINHO EVR; CARVALHO MLM. 2001. Relação entre o teste de deterioração controlada e o desempenho de sementes de milho em diferentes condições de estresse. Revista Brasileira de Sementes 23: 198-204.

RIBEIRO MCC; MARQUES BM; AMARRO FILHO J. 2001. Efeito da salinidade na germinação de sementes de quatro cultivares de girassol (Helianthus annuus L.). Revista Brasileira de Sementes, 23: 281-284.

SECCO LB; QUEIROZ SO; DANTAS BF; SOUZA YA. 2010. Qualidade de sementes de acessos de melão (cucumis melo) em condições de estresse salino. Revista Verde 5: 01-11.

SILVA EAA; PINHO EV; VIEIRA MGGC; CARVALHO MLM; MACHADO JC. 2000. Alterações de isoenzimas em sementes de milho infectadas por fungos. Pesquisa Agropecuária Brasileira 35: 1725-1732.

SILVA RN; LOPES NF; MORAES DM; PEREIRA ALA; DUARTE GL. 2007. Physiological quality of barley seeds submitted to saline stress. Revista Brasileira de Sementes 29: 40-44.

SRIVASTAVA DK; GUPTA VK; SHARMA DR. 1995. In vitro selection and characterization of water stress tolerant callus cultures of tomato (Lycopersicon esculentum L.). Indian Journal of Plant Physiology 38: 99-104.

TAIZ L; ZEIGER E. 2006. Fisiologia vegetal. Porto Alegre: Artmed. 719p.

TORRES SB; VIEIRA EL; MARCOS FILHO J. 2000. Efeitos da salinidade na germinação e no desenvolvimento de plântulas de pepino. Revista Brasileira de Sementes 22: 39-44.

TUNES LM; PEDROSO DC; MENEGHELLO GE; CASTRO MAS; BARROS ACSA; BADINELLI PG; MUNIZ MFB. 2010. Perfil enzimático em sementes de cevada em resposta a diferentes concentrações salinas. Revista Interciencia 35: 369-373.

VAN DER MOEZEL PG; BELL DT. 1987. The effect of salinity on the germination of some Western Australian Eucalyptus and Melaleuca species. Seed Science \& Technology 15: 239-246. 